July 2017

\title{
Bringing Students' Voices into Campus Conversations about Essential Learning Outcomes: A Survey of Students at a Mid-Sized State University
}

Carra L. Hood

Stockton University, carra.hood@stockton.edu

Follow this and additional works at: https://digitalcommons.georgiasouthern.edu/ij-sotl

\section{Recommended Citation}

Hood, Carra L. (2017) "Bringing Students' Voices into Campus Conversations about Essential Learning Outcomes: A Survey of Students at a Mid-Sized State University," International Journal for the Scholarship of Teaching and Learning: Vol. 11: No. 2, Article 11.

Available at: https://doi.org/10.20429/ijsotl.2017.110211 


\title{
Bringing Students' Voices into Campus Conversations about Essential Learning Outcomes: A Survey of Students at a Mid-Sized State University
}

\begin{abstract}
Stockton University, a mid-sized state university in the mid-Atlantic region of the United Stated, initiated the first of two pilots for implementation of its institutional outcomes during the fall semester 2014. At the beginning of that semester, in an effort to gauge students' attitudes university-wide toward the value of the outcomes, the director of the pilot administered an exploratory survey to the entire student population ( $\mathrm{N}=427)$. The survey contained eleven questions. The results indicate that students agree on their value. The student survey participants, however, identify five additional outcomes. Furthermore, student survey participants rank four of the student-identified outcomes of greater value than some of the institutional outcomes. The survey results also suggest that students could assume a more engaged role in campus conversations about core, institutional outcomes, thus, fostering authentic connection to the learning outcomes students seek and acquire while in college.
\end{abstract}

\section{Keywords}

student learning, institutional outcomes, undergraduate education, AAC\&U

\section{Creative Commons License}

(c) $($ ) $(\ominus$

This work is licensed under a Creative Commons Attribution-Noncommercial-No Derivative Works 4.0 License.

\section{Cover Page Footnote}

I would like to thank the Office of the Provost at Stockton University for supporting pilot implementation of institutional outcomes and administration of the exploratory survey. In addition, I am grateful to those faculty members and their students who participated in the pilot, openly sharing their experiences, and to the students who took the time to thoughtfully complete the survey. Their open-ended responses added meaningful insights to the answers they provided to multiple choice questions. Without the collaboration of everyone involved, I would not have been able to learn all that I did during the pilot and to put into use all that I gleaned from the exploratory survey. 


\title{
Bringing Students' Voices into Campus Conversations about Essential Learning Outcomes: An Exploratory Survey of Students at Stockton University
}

\author{
Carra L. Hood \\ School of General Studies, Stockton University, Galloway, NJ 08205, USA \\ (Received 22 October 2016; Accepted 7 February 2017)
}

\begin{abstract}
Stockton University, a mid-sized state university in the mid-Atlantic region of the United Stated, initiated the first of two pilots for implementation of its institutional outcomes during the fall semester 2014. At the beginning of that semester, in an effort to gauge students' attitudes university-wide toward the value of the outcomes, the director of the pilot administered an exploratory survey to the entire student population $(\mathrm{N}=427)$. The survey contained eleven questions. The results indicate that students agree on their value. The student survey participants, however, identify five additional outcomes. Furthermore, student survey participants rank four of the student-identified outcomes of greater value than some of the institutional outcomes. The survey results also suggest that students could assume a more engaged role in campus conversations about core, institutional outcomes, thus, fostering authentic connection to the learning outcomes students seek and acquire while in college.
\end{abstract}

\section{INTRODUCTION}

Stockton University (SU), a mid-sized state university in the mid-Atlantic region of the United States, initiated the first of two pilots for implementation of its institutional outcomes during the fall semester 2014. At the beginning of that semester, in an effort to gauge students' attitudes university-wide toward the value of the outcomes, the director of the pilot administered an exploratory survey to the entire student population. While the implementation pilot involved a subset of the entire student population, the exploratory survey targeted all students. Consequently, students from first to senior year, majoring in a wide-range of academic disciplines and professional specializations, responded to the survey request. The survey, borrowed from one administered to two classes of juniors and seniors at a mid-western state university (Walker, 2008), contained a single, open-ended, primary question: List five things that you think everyone should learn at college. As well, the survey asked four follow up questions, which provided students with opportunities to communicate the extent to which courses, faculty, co-curricular experiences, and selfdirection contribute to their learning. A final question prompted students to assess whether their grades reflect their learning. By borrowing this survey, the director hoped to find out if SU students considered the same outcomes essential to a college education as SU faculty members, professional staff, and administrators.

Many colleges and universities have sought to identify institutional outcomes over the past ten years in response to public debate about what students should learn in college, employers' complaints that graduates do not have adequate skills for the workplace, and pressure from the federal government for institutional accountability, transparent evidence of student learning, and reports on graduates' salaries in relation to the cost of their education and student loan debt. Some liberal arts institutions have adopted the Association of American Colleges and Universities (AAC\&U) essential learning outcomes as institutional outcomes. SU did not adopt AAC\&U's outcomes; although eight of the institution's ten outcomes overlap with AAC\&U's. Instead, a group of over one hundred faculty members, professional staff, and administrators attended a summer retreat in 2010 to discuss and ultimately identify ten educational outcomes deemed common to SU's academic and co-curricular learning experiences. Those institutional outcomes include: Adapting to Change, Communication Skills, Creativity \& Innovation, Critical Thinking, Ethical Reasoning, Global Awareness, Information Literacy \& Research Skills, Program Competence, Quantitative Reasoning, and Teamwork \& Collaboration.

Students did not attend the retreat or otherwise contribute to the process of identifying institutional outcomes. However, in the fall semester 2014, approximately 240 students taking twelve, primarily firstyear, courses were exposed to the institutional outcomes and would participate in the first pilot implementation because their teachers had signed on. Faculty members, professional staff, and administrators who attended the retreat agreed that the institutional outcomes grew out of the goals of liberal arts education and, rather than adding another layer to existing course design and assessment, the institutional outcomes provided a lexicon for the teaching and learning already taking place on the campus. Students might not agree with their teachers, though, so before launching full-scale implementation, the director of the pilot wanted to learn directly from students what outcomes they would like to achieve as a result of their college education. The exploratory survey was the director's attempt to include students' voices in the campus-wide discussion of institutional outcomes.

The director anticipated three possible findings from the survey. Students' responses to the survey could end up confirming the value of the ten institutional outcomes, confirming the value of some outcomes and not others, or demonstrating a mismatch. The two latter possibilities seemed more realistic survey findings than the former, as what faculty members set out to teach, much of which derives from faculty members' perceptions of what students need to learn, may not accord with what they in fact teach or what students learn, a large majority of which tends to evolve from students' questions, desires, struggles, and personal stories (Walker, 2008, p. 46; Cross, 1975, p. 54). 
The director expected students' responses to the survey to reflect the outcomes of what students want to learn rather than the outcomes of course goals established by their teacher, in other words to demonstrate some disconnection from the ten institutional outcomes.

Institutions do not commonly seek input from students on matters related to establishing institutional outcomes or to mapping the contours of students' learning. Kuh explains that teachers and administrators only reluctantly, if at all, relinquish their role articulating pedagogical goals and establishing ranked expectations for student learning (1998, p. 17). Generally, a group of assessors carries out institutional assessment of students' learning, using a rubric or other type of standardized assessment instrument designed to measure students' success completing an assignment or test against predetermined performance indicators and performance levels. Walker's study (2008) represents a departure from this assessment process because, as Walker notes (2008), it gives students an opportunity "to reflect on what they believe they should learn and what they have learned, rather than reflecting on or performing predetermined outcomes" (p. 47). Consequently, Walker's 2008 study provides one of the few guides for giving students a voice in the institutional assessment of their learning and in the delineation of the learning outcomes of their education. A progressive instance of involving students in assessment, the Wabash Provost-Scholars Program at North Carolina A \& T State University offers a model for training student assessors and using them to collaborate with faculty members in institutional assessment activities (https://wpscholars.wordpress.com/). Following the spirit of the Wabash Provost-Scholar Program and Walker's study (2008), the exploratory survey research conducted with students at SU aimed to create a method and rationale for including students' voices in efforts to establish, assess, and report the outcomes of students' learning while attending an institution of higher education.

\section{METHOD}

This study was prompted by two questions: I) Do students value SU's ten institutional outcomes? 2) Do these institutional outcomes accurately describe students' selfperception of their learning from first year to graduation? As a result of research for a survey instrument to answer these two questions, the director located Walker's 2008 study "What Do Students Think They (Should) Learn at College?: Student Perceptions of Essential Learning Outcomes." Not only does Walker's study include an instrument but it also approaches survey administration and analysis in a way that comports with the director's. In particular, the director, like Walker (2008), aimed to "[allow] participating students to reflect on what they believe they should learn" (p. 47) rather than asking them to respond to the ten institutional outcomes. SU created its institutional outcomes to capture students' learning in academic as well as co-curricular and extra-curricular learning. As well, SU intended for students to own the outcomes of their educational experience, that is, to develop the vocabulary and the metacognitive awareness to describe what and how they learned while in college.
Consequently, the questions on Walker's survey also suited the institutional design for SU's outcomes.

When the director contacted Walker for permission to borrow the survey instrument, Walker consented. The director, then, received Institutional Review Board (IRB) approval to survey students with the borrowed instrument. The survey, administered through SurveyMonkey, included the following questions.

Survey questions:

I) List 5 things you think everyone should learn at college.

[Fill in the blanks]

2) How effective have courses been in helping you accomplish the outcomes you listed?

[Rating scale: Not at all effective, More ineffective than effective, More effective than ineffective, Extremely effective]

3) Please explain your answer to the previous question, providing as much detail as you can. [Open-ended]

4) How effective have faculty been in helping you accomplish the outcomes you listed?

[Rating scale: Not at all effective, More ineffective than effective, More effective than ineffective, Extremely effective]

5) Please explain your answer to the previous question, providing as much detail as you can. [Open-ended]

6) How effective have co-curricular experiences been in helping you accomplish the outcomes you listed?

[Rating scale: Not at all effective, More ineffective than effective, More effective than ineffective, Extremely effective]

7) Please explain your answer to the previous question, providing as much detail as you can. [Open-ended]

8) How effective have you been at creating opportunities to accomplish the outcomes you listed?

[Rating scale: Not at all effective, More ineffective than effective, More effective than ineffective, Extremely effective]

9) Please explain your answer to the previous question, providing as much detail as you can. [Open-ended]

10) Do your grades reflect your learning? [Rating scale: Not at all, In some ways, To a large extent, Always]

II) Please explain your answer to the previous question, providing as much detail as you can. [Open-ended] 
The open-ended survey questions offered students a chance to explain the ways in which they perceive the four identified determinants of learning (faculty, courses, cocurricular activities, and self-direction) contribute to their success achieving the outcomes they listed as answers to the first survey question. The final survey question invited students to express their satisfaction with grades as indicators of their learning and educational outcomes.

According to survey protocol at $\mathrm{SU}$, an individual in the Division of Student Affairs sent out the survey and consent form to students' email accounts. In addition, the director sent a note to the faculty listserv, alerting the full faculty to the survey and briefly explaining it so that faculty members could answer any questions their students might have. A second email blast went out a week and a half after the first one. The survey remained active for three weeks.

Once the survey closed, the director collected students' responses. In order to answer the questions prompting the survey, the director needed to align students' responses to the first survey question to the ten institutional outcomes. That required norming to establish inter-rater reliability; three faculty members and three students participated in that process. To facilitate norming, the director created an Excel spreadsheet with eleven columns. The left-hand column contained all of the students' responses to the first question, and the other ten columns each had a header containing the name of one institutional outcome followed by the institutional definition of the outcome, i.e., Adapting to Change and The ability to successfully engage and navigate new or unfamiliar circumstances or create opportunities (see the chart of SU's Essential Learning Outcomes and their definitions at http://www.stockton.edu/elos). The three faculty members and the three students independently aligned student responses to institutional outcomes by putting an $X$ in the column under the name of the appropriate institutional outcome. They did not put an $X$ in any column when a student response failed to align with an institutional outcome. Then, they compared their alignments, discussing and making adjustments as necessary and when possible. Many of the students' responses to the first question either matched the language of institutional outcomes exactly or contained closely-related synonyms. For instance, when students included adaptability among the five important outcomes, the group performing the analysis aligned that with the institutional outcome Adapting to Change. In those instances when students' responses did not align with institutional outcomes, the group analyzing the survey responses coded and classified them, ultimately adding five new categories: Career Preparation, Experiential Learning, General Knowledge, Personal Understanding/SelfImprovement, and Social Skills. For the purposes of this analysis, the group analyzing the survey responses referred to the new categories as student-identified outcomes to distinguish them from the ten outcomes identified by faculty, professional staff, and administrators at the summer retreat in 2010 .

\section{RESULTS}

Survey Question I: List 5 things you think everyone should learn at college

The alignment of student responses to institutional outcomes appears in the two tables below. Student responses that do not align with institutional outcomes represent $27 \%$ of student-identified outcomes; these are collected in the last row and organized into five subcategories: Career Preparation (7\%), Experiential Learning (4\%), General Knowledge (4\%), Personal Understanding/Self Improvement (6\%), and Social Skills (6\%). Student-identified outcomes do overlap with institutional outcomes; however, 4 student-identified outcomes (Career Preparation, Experiential Learning, Personal Understanding/Self Improvement, and Social Skills) appear among the top ten student-identified outcomes, and four institutional outcomes fall outside the top ten studentidentified outcomes (Ethical Reasoning, Teamwork \& Collaboration, Information Literacy \& Research Skills, and Creativity \& Innovation). Student responses indicate the importance of these four institutional outcomes, yet students rank them of less importance than Career Preparation, Experiential Learning, Personal Understanding/Self Improvement, and Social Skills, all of which are not considered essential institutional outcomes.

Table I. Student Survey, Ordering Outcomes, N=427

\begin{tabular}{|l|c|c|}
\hline \multicolumn{1}{|c|}{ Outcomes } & $\begin{array}{c}\text { Number } \\
\text { of Student } \\
\text { Responses }\end{array}$ & $\begin{array}{c}\text { Percent of } \\
\text { Student } \\
\text { Responses }\end{array}$ \\
\hline Communication Skills & 68 & 16 \\
\hline Adapting to Change & 57 & 13 \\
\hline Quantitative Reasoning & 51 & 12 \\
\hline Program Competence & 43 & 10 \\
\hline Career Preparation & 29 & 7 \\
\hline Global Awareness & 27 & 6 \\
\hline Personal Understanding/Self- & 27 & 6 \\
\hline Improvement & 24 & 6 \\
\hline Social Skills & 21 & 5 \\
\hline Critical Thinking & 19 & 4 \\
\hline Experiential Learning & 18 & 4 \\
\hline Ethical Reasoning & 16 & 4 \\
\hline General Knowledge & 13 & 3 \\
\hline Teamwork \& Collaboration & 10 & 2 \\
\hline $\begin{array}{l}\text { Information Literacy } \& \\
\text { Research Skills }\end{array}$ & 4 & 1 \\
\hline Creativity \& Innovation & 10 \\
\hline
\end{tabular}

Key: Institutional outcomes appear in black font; student-identified outcomes that do not align with institutional outcomes appear in red font.

Survey Questions 2 and 3: How effective have courses been in helping you accomplish the outcomes you listed?

Student survey respondents note that courses are extremely effective (24.5\%) and more effective than ineffective (57.3\%) in helping them to accomplish their 
selected student-identified outcomes. Student survey respondents also indicate that courses are not at all effective and more ineffective than effective in $3.6 \%$ and $6.4 \%$ of cases, respectively. One of the students who does not find courses effective, explains that "I feel I learned most of these [selected outcomes] at my previous college"; another clarifies that "I haven't learned much of what I listed; I spend more time in general classes that won't ever matter to me rather than in learning what I think I should be learning."

\section{Table 2. Student Survey, Effectiveness of Courses, $N=110$}

How effective have courses been in helping you accomplish the outcomes you listed?

\begin{tabular}{lcc}
\multicolumn{1}{c}{$\begin{array}{c}\text { Answer } \\
\text { Options }\end{array}$} & $\begin{array}{c}\text { Response } \\
\text { Percent }\end{array}$ & $\begin{array}{c}\text { Response } \\
\text { Count }\end{array}$ \\
$\begin{array}{l}\text { Not at all } \\
\text { effective }\end{array}$ & $3.6 \%$ & 4 \\
$\begin{array}{l}\text { More ineffective } \\
\text { than effective }\end{array}$ & $6.4 \%$ & 7 \\
$\begin{array}{l}\text { More effective } \\
\text { than ineffective }\end{array}$ & $57.3 \%$ & 63 \\
$\begin{array}{l}\text { Extremely } \\
\text { effective } \\
\text { Other (please }\end{array}$ & $24.5 \%$ & 27 \\
specify) & $8.2 \%$ & 9
\end{tabular}

Survey Questions 4 and 5: How effective have faculty been in helping you accomplish the outcomes you listed?

Student survey respondents report that faculty are extremely effective $(39.1 \%)$ and more effective than ineffective $(46.4 \%)$ in helping them to accomplish their selected student-identified outcomes. Comments from students who respond in this way highlight faculty members as "an integral part of my learning process, teaching me and challenging me," note that faculty members "believe that I am better than what I am now and want to see me be a better person, not just telling me what I need to hear to secure their paychecks," and share that "without their [faculty members'] encouragement, I would have dropped out." A small percentage of student survey respondents consider faculty members not at all effective (1.8\%) and more ineffective than effective $(6.4 \%)$ in helping them to achieve their goals.

Table 3. Student Survey, Effectiveness of Faculty, $N=\mid$ I 0

How effective have faculty been in helping you accomplish the outcomes you listed?

\begin{tabular}{|c|c|c|}
\hline $\begin{array}{l}\text { Answer } \\
\text { Options }\end{array}$ & $\begin{array}{l}\text { Response } \\
\text { Percent }\end{array}$ & $\begin{array}{c}\text { Response } \\
\text { Count }\end{array}$ \\
\hline $\begin{array}{l}\text { Not at all } \\
\text { effective }\end{array}$ & $1.8 \%$ & 2 \\
\hline $\begin{array}{l}\text { More ineffective } \\
\text { than effective }\end{array}$ & $6.4 \%$ & 7 \\
\hline $\begin{array}{l}\text { More effective } \\
\text { than ineffective }\end{array}$ & $46.4 \%$ & 51 \\
\hline $\begin{array}{l}\text { Extremely } \\
\text { effective }\end{array}$ & $39.1 \%$ & 43 \\
\hline $\begin{array}{l}\text { Other (please } \\
\text { specify) }\end{array}$ & $6.4 \%$ & 7 \\
\hline
\end{tabular}

Survey Questions 6 and 7: How effective have cocurricular experiences been in helping you accomplish the outcomes you listed?

Student responses to this question vary based on the extent to which they have joined clubs and organizations or have the time to attend co-curricular events. Commuters, student parents, and students who work full or part-time tend to select the "other" option, which accounts for the large percentage of "other" responses (24.5\%). Of those student survey respondents who could contribute to clubs and organization or do attend co-curricular events, $16.4 \%$ find them extremely effective and $32.7 \%$ find them more effective than ineffective in helping them accomplish their selected student-identified outcomes. However, 26.3\% report that co-curricular experiences are not at all effective or more ineffective than effective. Comments from students who find co-curricular experiences effective range from the "topics covered dive into real-world applications of information taught in the classroom" to "I learned leadership, time management, and creativity...[and] critical thinking skills in clubs" and "my experience in my club helped me work with others and speak publicly."

\begin{tabular}{|c|c|c|}
\hline \multicolumn{3}{|c|}{$\begin{array}{l}\text { How effective have extra-curricular experience } \\
\text { been in helping you accomplish the outcomes yo } \\
\text { listed? }\end{array}$} \\
\hline $\begin{array}{l}\text { Answer } \\
\text { Options }\end{array}$ & $\begin{array}{c}\text { Response } \\
\text { Percent }\end{array}$ & $\begin{array}{c}\text { Response } \\
\text { Count }\end{array}$ \\
\hline $\begin{array}{l}\text { Not at all } \\
\text { effective }\end{array}$ & $14.5 \%$ & 16 \\
\hline $\begin{array}{l}\text { More ineffective } \\
\text { than effective }\end{array}$ & $11.8 \%$ & 13 \\
\hline $\begin{array}{l}\text { More effective } \\
\text { than ineffective }\end{array}$ & $32.7 \%$ & 36 \\
\hline $\begin{array}{l}\text { Extremely } \\
\text { effective }\end{array}$ & $16.4 \%$ & 18 \\
\hline $\begin{array}{l}\text { Other (please } \\
\text { specify) }\end{array}$ & $24.5 \%$ & 27 \\
\hline
\end{tabular}

Survey Questions 8 and 9: How effective have you been at creating opportunities to accomplish the outcomes you listed?

Student survey respondents overwhelming note that they are extremely effective (30.0\%) or more effective than ineffective $(54.5 \%)$ at creating opportunities to accomplish their selected student-identified outcomes. Some of those who respond this way emphasize that they work with tutors when necessary, study hard, create study groups, use the University library, avail themselves of the resources in the career center, and speak with professors after class or during office hours. $8.1 \%$ report that they are not at all effective $(3.6 \%)$ or more ineffective than effective $(4.5 \%)$ in creating opportunities to accomplish their goals. As clarification, some who respond in this way admit that they had not tried. For instance, one student explains that "I sign up for classes, that's all." Another notes that "I can be lazy; I don't always go for help"; still another student reveals that "I could be more effective at contributing to my own learning." 


\begin{tabular}{|c|c|c|}
\hline \multicolumn{2}{|c|}{$\begin{array}{l}\text { How effective have you } \\
\text { opportunities to accomplish } \\
\text { listed? }\end{array}$} & $\begin{array}{c}\text { at cre } \\
\text { outcomes }\end{array}$ \\
\hline $\begin{array}{l}\text { Answer } \\
\text { Options }\end{array}$ & $\begin{array}{l}\text { Response } \\
\text { Percent }\end{array}$ & $\begin{array}{c}\text { Response } \\
\text { Count }\end{array}$ \\
\hline $\begin{array}{l}\text { Not at all } \\
\text { effective }\end{array}$ & $3.6 \%$ & 4 \\
\hline $\begin{array}{l}\text { More ineffective } \\
\text { than effective }\end{array}$ & $4.5 \%$ & 5 \\
\hline $\begin{array}{l}\text { More effective } \\
\text { than ineffective }\end{array}$ & $54.5 \%$ & 60 \\
\hline $\begin{array}{l}\text { Extremely } \\
\text { effective }\end{array}$ & $30.0 \%$ & 33 \\
\hline $\begin{array}{l}\text { Other } \\
\text { specify) }\end{array}$ & $7.3 \%$ & 8 \\
\hline
\end{tabular}

Survey Questions 10 and I I: Do your grades reflect your learning?

Only 5.5\% of student survey respondents report that grades do not at all reflect their learning. Comments from students who respond in this way range from "no, grades are not a true reflection of learning" to "grades mainly reflect the amount of effort I have put into my work, but not necessarily the amount that I have learned" and "because I am so focused on getting good grades and maintaining my GPA, there's less time on actually learning [and] I want to learn." $15.5 \%$ note that grades always reflect their learning, and $34.5 \%$ indicate that grades reflect their learning to a large extent. A comparable percent of students (38.2\%) specify that grades reflect their learning in some ways, but not in others. Comments from students with this response reveal their sense that doing well in school and achieving good grades are distinct from lessons learned from social life, personal experiences, and on-the-job training.

Table 6. Student Survey, Grades Represent Learning, $\mathrm{N}=110$

Do your grades reflect what you have learned?

\begin{tabular}{l|cc|}
\hline $\begin{array}{l}\text { Answer } \\
\text { Options }\end{array}$ & $\begin{array}{c}\text { Response } \\
\text { Percent }\end{array}$ & $\begin{array}{c}\text { Response } \\
\text { Count }\end{array}$ \\
\hline Not at all & $5.5 \%$ & 6 \\
\hline In some ways & $38.2 \%$ & 42 \\
\hline To a large extent & $34.5 \%$ & 38 \\
\hline $\begin{array}{l}\text { Always } \\
\text { Other (please }\end{array}$ & $15.5 \%$ & 17 \\
specify) & $6.4 \%$ & 7 \\
\hline
\end{tabular}

\section{DISCUSSION}

This study has a number of limitations that warrant mentioning. First of all, the survey instrument, while wellintentioned, needs refinement that could be achieved through broad-based testing to strengthen validity and reliability, followed by relevant revision and additional research. As well, a revised instrument should enhance the potential for triangulating the data by including questions that collect information about respondents' demographics. Revising the instrument to include the established institutional outcomes could prevent guesswork or inaccuracy connecting students' responses to institutional outcomes. Furthermore, this study sampled a small population of students. Although the results have meaning and suggest that student respondents and the faculty members, professional staff, and administrators who identified SU's ten institutional outcomes agree on their value, further research at other types, sizes, and locations of institutions, would help to confirm the results of this exploratory survey. In addition, further research, specifically research involving a control group, would provide additional evidence for strengthening or reconsidering the conclusion that student learning improves with student involvement in identifying and defining institutional outcomes. Finally, SU student survey respondents indicated the importance of five additional outcomes and rank four of the student-identified outcomes of greater value than some identified by SU faculty members, professional staff, and administrators. Additional research could reinforce the relevance, or potentially the variability, of these particular studentidentified outcomes across campuses and types of institutions.

The Division of Student Affairs at many institutions offers students opportunities for career preparation, personal growth, socializing, and community engagement. Professional staff and, sometimes, student interns that work with Student Affairs, creates programming that complements classroom learning and, at SU, provide learning experiences intentionally designed for students to develop proficiency in institutional outcomes as well as student-identified outcomes. The survey results indicate, however, that despite the fact that faculty members and leaders of co-curricular activities may create assignments, projects, or exercises that incorporate activities associated with the student-identified outcomes, survey respondents express interest in receiving more formal acknowledgement of the institution's commitment to their learning in these areas and to their work achieving these outcomes. Since students were not involved in identifying SU's institutional outcomes or in ongoing conversations about the outcomes following the retreat in 2010 , their voices have not had a presence in cross-campus conversations, and the five additional, student-identified outcomes have not been incorporated into the institutional outcomes. This survey offered students an opportunity to demonstrate their stake in future conversation about or revision of institutional outcomes.

The survey results have implications for SU, implications that, as Bourdieu (1988) notes, relate directly to the social structures operative in the university culture, to the locus of power within that social space, and to the perpetuation of faculty and administrative control over knowledge production, dissemination, and valuation. The survey results indicate that student respondents recognize the important roles the institution, faculty members, cocurricular educators, courses, and Student Affairs' programming have to their education; however, the survey results also suggest that students bring their goals, and the desire to accomplish their goals, to each of their learning experiences. Although seven student-identified outcomes 
overlap with institutional outcomes, the institution might acknowledge additional student-identified outcomes by creating ways for students to more fully enter the campus discussion about learning outcomes. Alternatively, the University might consider regularly revisiting and revising institutional outcomes in collaboration with and in response to input from students attending the institution. These actions would require some modification to SU's campus culture regarding the nature of relationships between students and faculty members, professional staff, and administrators. Barr and Tagg (1995) identify the need for restructuring institutions to respond to the values of a student-centered approach to education and to learning ( $p$. 14), a kind of restructuring that aligns with the survey results and conclusions presented in this article. Hutchings, Hunter, and Ciccone (20I I) imagine institutions that deploy the benefits of a focus on student learning, value the principles developed through the scholarship of teaching and learning, and encourage the active role of students taking charge of their learning for the purposes of changing institutional culture (3). If an institution of higher education grants students an equal voice, or even some voice, in deciding what they learn, in particular what outcomes they achieve, the institution has set the stage for a more inclusive campus culture, one that distributes power more broadly than in the past and, as Hutchings, Hunter, and Ciccone (20II) emphasize sets the stage for "a broader transformation in the intellectual culture of higher education," (4) where student learning truly rests at the center of the educational enterprise.

Research indicates that, across the United States, students do not usually have a role in determining institutional outcomes. In some instances, faculty members do not have a role, either; one administrator, or a small group of administrators, may choose to adopt AAC\&U's essential learning outcomes, for instance, the Degree Qualifications Profile (DQP), or outcomes from another national organization. This practice, while not the practice at SU, which did invite faculty members' input, might result in establishing a set of learning outcomes that matters across individual campuses. However, it also might not. In addition, an administratively-driven process could result in faculty members' distancing institutional outcomes from course goals and the dynamic work taking place in the classroom or in campus-wide disregard for institutional outcomes, leading to ignorance of, even more counterproductive, disdain for them. When faculty members have a role in identifying institutional outcomes, they may, therefore, buy-in to the institutional outcomes; begin to incorporate them into courses, assignments, and programs; and participate in institutional assessment, as is the case at SU.

Students may not share their faculty members' commitment to the institutional outcomes, though, beyond their course grade. AAC\&U and Hart Research Associates (2016) note, for instance, that over the past seven years, students' understanding of institutional outcomes has not kept pace with institutions' adoption of learning outcomes. Hutchings (2016) argues that students have "a critical role...in achieving the kind of connected, integrative learning" characteristic of a liberal arts education (p. 12). However, Hutchings (2016) also argues that "it is the responsibility of educators...to create the pedagogical, curricular, and co-curricular supports and scaffolding that give students the greatest likelihood of achieving" success in the $21^{\text {st }}$ century (p. 12). Integrative learning, in this case, means proficiency on a scale of pre-determined outcomes measured by standardized assessments.

According to Hutchings (2016), students have a critical role in demonstrating integrative learning but not in creating the contexts, conditions, or outcomes of that learning. The findings from this survey reveal that a majority of students accept their place as recipients of knowledge and products of the institution they attend. Some students, though, disconnect grades from learning and recognize that not all of what they would like to learn at school occurs in the context of their courses and co-curricular activities. The survey results also indicate that students perceive themselves contributing to their own learning to the same extent as faculty and courses. In other words, students value their self-regulated exploration as much as they do course performance rated by grades. Barr and Tagg (1995) agree with Hutchings (2016) that teachers can create environments for student learning (p. 15) and that, when they design successful learning contexts, students learn by discovery (p. 15). However, like Hutchings, they do not take the next step and suggest that students can - and perhaps should - occupy positions in relation to their own learning that make them productive partners in identifying institutional learning outcomes or participating in formative and summative self-evaluation.

Tagg (2003) points to Olivet College, a small, private, faith-based institution, as one example of a learning paradigm college that puts student learning at the center of the educational experience (p. 144-149). Olivet requires students to demonstrate their proficiency in achieving institutional and program outcomes, but it also offers students the opportunity to identify, work toward, and display individualized goals (Tagg, 2003, p. 144-149). This compromise position, the Olivet Plan (http://www.olivetcollege.edu/olivet-plan), relies on student composition of a personal portfolio, successful completion of a series of general education courses, and enrollment in a portfolio seminar each semester. Tagg (2003) recognizes the structure of Olivet's undergraduate education as "a fairly unusual picture in American higher education: a college that... repeatedly thrusts ownership of learning and learning goals upon the student, that explicitly declares student sovereignty over their own learning at the beginning, and that calls on students to continuously reclaim that sovereignty as long as they are students" (p. 148). Olivet's structure, while clearly uncommon among institutions of higher education in the United States and, as Tagg notes, invested in students' responsibility for some of their learning outcomes, does not appear to involve students in conversations to identify and to revisit institutional learning outcomes. Survey results from students at SU indicate that students value faculty guidance and institutional learning frameworks; however, the results also suggest that students could assume a more engaged role in campus conversations about core, institutional outcomes.

For instance, in contrast to students' reliance on grades as markers of their learning, the survey results show 
that students want to learn and know what they would like to learn or, if not that, know what kinds of educational experiences they would like to have and from which they would like to learn. Despite not having a role in determining the institutional outcomes, much of what students' report wanting to learn comports with what their teachers and the institution they attend deems they need to learn. However, the overlap does not justify students' absence from the process; nor does it guarantee buy-in, understanding, or awareness of the outcomes when students receive them as course requirements or as features of assessment. At SU, faculty members bring institutional outcomes into the classroom; students encounter them as predetermined course goals, against which teachers measure their performance. To that extent, the outcomes reside outside of students, as students did not collaborate in identifying or defining them. Faculty members and the institution they attend do not perceive students as agents who bring learning goals and desired outcomes into classrooms; the survey results demonstrate, though, that students do, in fact, arrive on campus primed with specific, well-articulated expectations and desired outcomes for their college education, a conclusion that Walker also draws from the students who participated in his study (p. 58).

The involvement of SU faculty members in the identification of institutional outcomes has led directly to faculty members' investment in their implementation across the campus and in courses. Not surprisingly, their involvement in that initial process has proven a primary factor in faculty members' ongoing commitment to curriculum mapping, use of electronic portfolios, and participation in two pilot implementations of institutional outcomes in major and minor programs and general education courses. Institutional outcomes have become a shared vocabulary among faculty members, professional staff, and administrators across the campus as a result. SU students' investment in institutional outcomes comes as a consequence of exposure to them in courses and cocurricular activities. As a result, students may attach them to their teachers and their courses, principally because their teachers deliver them, not because students know what they mean or what kind of value they might have outside of the classroom and in their lives.

As has been the case with faculty members, students' learning in courses that help guide students' awareness and proficiency in one or more institutional outcome could lead to genuine investment. The survey findings raise the possibility that engaging students as collaborators appears worthwhile, since those who work in institutions of higher education share educational values with students. If institutions create opportunities to bring students into conversations about learning outcomes, rather than leaving them out, that effort could result in reinforcing the value of, adding to, or revising existing outcomes while also increasing students' success as well as ownership of their learning. As Walker notes, not involving students results in "a limited view of the learning that takes place on any given college campus" (p. 58). Students' involvement, in other words, can foster authentic connection to the learning outcomes they seek and acquire while in college.

\section{ACKNOWLEDGEMENTS}

I would like to thank the Office of the Provost at Stockton University for supporting pilot implementation of institutional outcomes and administration of the exploratory survey. In addition, I am grateful to those faculty members and their students who participated in the pilot, openly sharing their experiences, and to the students who took the time to thoughtfully complete the survey. Without the collaboration of everyone involved, I would not have been able to learn all that I did during the pilot and to put into use all that I gleaned from the exploratory survey.

\section{REFERENCES}

Association of American Colleges and Universities (AAC\&U). (n.d.). Essential learning outcomes. https://www.aacu.org/leap/essential-learningoutcomes

Association of American Colleges and Universities (AAC\&U) and Hart Research Associates. (2016). Recent trends in general education design, learning outcomes, and teaching approaches: Key findings from a survey among administrators at AAC\&U member institutions. Washington, D.C.: Hart Research Associates. https://www.aacu.org/sites/default/files/files/LEAP/201 5 Survey Report2_GEtrends.pdf

Barr, R. A., and Tagg, J. (1995). From teaching to learning: A new paradigm for undergraduate education. Change, 13-25.

Bourdieu, P. (1988). Homo Academicus. Stanford, CA: Stanford University Press.

Cross, K. P. (1975). Learner-centered curricula. In D. W. Vermilye (ed.) Learner-Centered Reform (54-65). San Francisco, CA: Jossey-Bass.

Degree Qualifications Profile (DQP). (2016). Lumina Foundation. http://degreeprofile.org/

Hutchings, P. (n.d.). Aligning educational outcomes and practices. National Institute for Learning Outcomes Assessment. http://learningoutcomesassessment.org/documents/O ccasional\%20Paper\%2026.pdf

Hutchings, P., Hunter, M. T., \& Ciccone, A. (20II). The Scholarship of Teaching and Learning: Institutional Integrational Impact. San Francisco, CA: Jossey-Bass.

Kuh, G. (1998). Lessons from the mountains. About Campus, May-June, 16-2I.

North Carolina A \& T State University. (n.d.). Wabash Provost-Scholar https://wpscholars.wordpress.com/

Olivet College. (n.d.). The Olivet plan. http://www.olivetcollege.edu/olivet-plan

Stockton University. (n.d.). Essential Learning Outcomes. http://www.stockton.edu/elos

Tagg, J. (2003). The Learning Paradigm College. San Francisco, CA: Jossey-Bass.

Walker, P. (2008). What do students think they (should) learn at college?: Student perceptions of essential learning outcomes. Journal of the Scholarship of Teaching and Learning, 8(I), 45-60. 